\title{
Influence Factors of Sternal Healing and Comparison of Different Sternal Closure Methods $₫ A$ Retrospective Analysis
}

\section{Xuanren Long ( $\square$ zongxuanren96@163.com )}

Suzhou University https://orcid.org/0000-0002-0661-6119

\section{Kun Mei}

Third Affiliated Hospital of Soochow University: Changzhou First People's Hospital

\section{Yongxiang Qian}

Third Affiliated Hospital of Soochow University: Changzhou First People's Hospital

\section{Xiaoyin Zhang}

Third Affiliated Hospital of Soochow University: Changzhou First People's Hospital

\section{Bin Wang}

Third Affiliated Hospital of Soochow University: Changzhou First People's Hospital

\section{Dongmei Di}

Third Affiliated Hospital of Soochow University: Changzhou First People's Hospital

\section{Research article}

Keywords: median sternotomy, radiographic sternal healing, thickness of the cortical bone, a new method of sternal closure

Posted Date: July 20th, 2021

DOI: https://doi.org/10.21203/rs.3.rs-687528/v1

License: (c) (1) This work is licensed under a Creative Commons Attribution 4.0 International License. Read Full License 


\section{Abstract \\ Background}

We determined the factors affecting sternum healing after a median sternotomy based on a retrospective analysis and compared the stability of different sternal closure techniques.

\section{Methods}

We collected information involving patients who underwent a median sternotomy in Changzhou First Hospital from 2014-2019 and had chest CT examinations 1-24 months postoperative, Main outcome includes the average of sternal healing score at the five specific anatomic levels and the adverse event of transverse displacement of sternum.

\section{Results}

In the short term healing group, Sternal score was only correlated with postoperative time $(H R=0.18$, $95 \% \mathrm{Cl}: 0.135-0.225, \mathrm{p}<0.001)$. In the long term healing group,old people had a higher risk of poor sternal healing than young (Age, $\mathrm{HR}=-0.028,95 \% \mathrm{Cl}:-0.05,-0.006, \mathrm{p}=0.013)$. Patients with left internal mammary artery grafting (LIMAG) had a high risk of poor sternal healing (HR=-0.444, Cl:-0.869-0.019, $p=0.045)$. By binary logistic regression, It could be found that steel wire fixation was a favorable factor to prevent the transverse displacement of sternum $(H R=0.122,95 \% \mathrm{Cl}: 0.007-0.651, p=0.047)$.

\section{Conclusion}

In summary, advanced age and internal mammary artery interception are risk factors that affect sternal healing based on imaging findings. this new method of sternal closure provides an effective way of ensuring sternal stability of both sternal plates and reduces the risk for complication after cardiac surgery in high-risk patients.

\section{Background}

Median sternotomy is one of the most common incision methods in heart surgery[1]. It provides excellent exposure of the heart,which is helpful for surgeons to operate[2]. Currently, the main focus of research involves the complications from median sternotomy, while sternum healing has not attracted widespread attention. Unlike the significant morbidity and mortality of postoperative sternal complications[3-5], poor sternal healing is more common in elderly patients[6], but most cardiothoracic surgeons overlook this problem because of its low risk. The morbidity of chronic pain after cardiac surgery, which has an adverse impact on health-related quality of life, is up to $56 \%$ [7]. A prospective study conducted by $\mathrm{H}$. K. Gjeilo[8] showed that $3.8 \%$ patients had chronic pain after 5 years. Prophase of sternal healing is related 
to sternal complications. One of the cause of postoperative deep sternal wound infections is malabsorption of sternal hematoma which leads to failure to form an effective dead space[9-10]. Through the analysis of the factors affecting the sternum healing, it is helpful to take appropriate surgical methods and postoperative care that accelerate the prophase of sternal healing and reduce the incidence of complications for the high-risk groups with poor sternum healing. The purpose of the study was to investigate determinants of sternal healing and estimate the effect of titanium plate compared to wire cerclage on sternal motion after cardiac surgery.

\section{Methods}

\section{Study design}

This retrospective study enrolled 122 patients who were examined with chest CT one to twenty-four months after cardiac surgery at the Third affiliated Hospital of soochow University, Changzhou, China.The chest CT imaging included the whole sternum allows us to evaluate sternal healing after operation. Inclusion criteria included patients aged 18-80 years undergoing elective cardiac surgery via a median sternotomy. Exclusion criteria included severe chronic obstructive pulmonary disease, history of taking immunosuppressive drug or autoimmune disease, history of osteoporosis and bone dysplasia, history of second thoracotomy, hemodialysis and placement of an aortic balloon regurgitation device during perioperative, history of renal insufficiency, complications from median sternotomy. All patients reexamined by chest CT scans one week after cardiac surgery and sternal was reducted well.

The baseline characteristics of patients were as follows: gender, EF, history of hypertension, history of pulmonary hypertension, internal mammary artery injury, a history of diabetes, body mass index (BMI), age, operative time, postoperative time, fixation method, the cortical thickness (the average thickness of the anterior and posterior sternal cortex at the midline of the five specific anatomic levels), the thickness of the sternum (the average thickness of the sternum at the midline of the five specific anatomic levels). Main outcome included the average of sternal healing score at the five specific anatomic levels and the adverse event of transverse displacement of sternum.

\section{Surgical methods}

The sternum was closed by one of the two following methods: titanium plates (Sternal Fixation System; Was-ton Medical Appliance Co. Ltd.), in which four plates are used in the first, second, third, and fourth or fifth intercostal spaces; and closure of the sternum with 5-7 metal wires (Surgical Stainless Steel Suture; Ethicon, LLC) as a single interrupted suture or a figure-of-eight suture. On the method of closure, the patients were divided into three groups(sternum plate groups, wire groups and mixed fixation groups). The surface of sternum was smeared with nonabsorbable bone wax to stop bleeding. A few patients used a new fixation method. One half of the titinium plate was placed on one side only where the region had been fixed with a 8-shaped steel wire, and then, the titinium plate around the 8-shaped steel wire allowing afirm approximation of the two sternal halves, followed by placement of the other half of the plate. The configuration of the plate around the wire prevents wire cutting through the bone and provides 
360-degree stabilization. After all plates and wires were secured, the soft tissue was closed with $2-0$ Polybutylate coated braided Polyester Suture and the skin was closed with 4 - 0 Polybutylate coated braided Polyester Suture (ETHIBOND EXCEL, Shanghai, China).

\section{Outcome measures}

The endpoint of the study was sternal healing which determined by independend radiologists using CT scans and a validated evaluation method. Five specific anatomic levels (Manubrium, Top of aortic arch, Aortopulmonary window, Main pulmonary artery, Aortic root)were selected by two different radiologists with senior title for evaluation. Radiologists scored independently each location using a 6-point scale(0: no sign of healing, 1: minimal healing, 2: mild healing, 3: moderate healing, 4: partial synthesis, 5: complete synthesis). Sternal union was defined as a mean score of $\geq 3$.After kapper-test,the average value of scores from two radiologists was taken as the final result. Cortical thickness and sternal thickness were also measured manually by the two radiologists through CT scan results.

\section{Statistical analysis}

In order to assess the risk factors for poor sternal healing, we divided the patients into two groups: a short term healing group (the $S$ group) and a long term healing group (the $L$ group). Multiple linear regression were performed to identify risk factors for poor sternal healing at the $S$ group and the $L$ group. Continuous data were presented as mean \pm standard deviation and evaluated with t-test. Categorical data, summarized as a number(\%), were evaluated with Chi square test and Fisher test. Except that a significance level of 0.1 was used in the univariate linear regression analysis to select the variables for the multiple linear regression, $p$-values less than 0.05 were considered to indicate statistical significance. We made an propensity score matching (PSM)[11] to control bias by "Matchlt" R package[12]. The age was the adjusted variable used to PSM for patients by a nearest methods with a case-control ratio of 1:3 (Fig. 1). All statistical analyses were performed by R software (version 3.6.3).

\section{Results}

\section{Participants and characteristics}

122 patients were enrolled, including 77 males and 45 females, with an average age of $57.83 \pm 11.80$ years. The mean BMI was $61.6 \pm 11.3 \mathrm{~kg}$. 64 patients underwent Off pump coronary artery bypass grafting. Isolated valve procedures was performed in 58 patients. The mean CT examination time after surgery was $12.53 \pm 8.43$ months. The two radiologists determined the healing score based on the sternal CT scan (Fig. 2). The results were analyzed by a Kapper-test. The results showed that the scoring method was reliable and repeatable (Table 1). There was a significant bias in the research data because surgeons always choose an appropriate sternal closure method according to the specific situation of patients (Table 2). To control bias, we made an propensity score matching (PSM) and 102 patients were selected for the subsequent analyses. Table 3 displayed a summary of the demographic and clinical characteristics of those patients after PSM. 
Table 1

Consistency test of sternal healing score

\begin{tabular}{|c|c|}
\hline & Kapper vaule \\
\hline ૧ & 0.852 \\
\hline ૧ & 0.831 \\
\hline ૧ & 0.798 \\
\hline ૧ & 0.882 \\
\hline ૧ & 0.799 \\
\hline
\end{tabular}


Table 2

Demographic and clinic characteristics for eligible patients

\begin{tabular}{|c|c|c|c|c|}
\hline Characteristic & Steel suture & Titanium plates & Mixed fixation & p \\
\hline$n$ & 19 & 88 & 15 & \\
\hline \multicolumn{5}{|l|}{ Gender } \\
\hline Female & 12(63.16) & $56(63.64)$ & $9(60.00)$ & 0.964 \\
\hline Male & $7(36.84)$ & $32(36.36)$ & $6(40.00)$ & \\
\hline Age & $51.32 \pm 14.83$ & $60.50 \pm 10.02$ & $50.40 \pm 11.64$ & $<0.001$ \\
\hline High & $167.63 \pm 11.40$ & $164.85 \pm 7.59$ & $167.20 \pm 5.09$ & 0.282 \\
\hline Weight & $65.37 \pm 13.04$ & $66.34 \pm 10.73$ & $64.80 \pm 11.07$ & 0.855 \\
\hline BMI & $23.04 \pm 2.54$ & $24.36 \pm 3.37$ & $23.07 \pm 2.85$ & 0.131 \\
\hline \multicolumn{5}{|l|}{ NYHA } \\
\hline ૧ & $5(26.32)$ & $24(27.27)$ & $2(13.33)$ & 0.125 \\
\hline ૧ & $5(26.32)$ & $30(34.09)$ & $9(60.00)$ & \\
\hline ૧ & $8(42.11)$ & $34(38.64)$ & $4(26.67)$ & \\
\hline ૧ & $1(5.26)$ & $0(0.00)$ & $0(0.00)$ & \\
\hline \multicolumn{5}{|c|}{ Pulmonary hypertension } \\
\hline Yes & $13(68.42)$ & $77(87.50)$ & $12(80.00)$ & 0.116 \\
\hline No & $6(31.58)$ & $11(12.50)$ & $3(20.00)$ & \\
\hline \multicolumn{5}{|l|}{ LIMAT } \\
\hline Yes & $9(47.37)$ & $40(45.45)$ & $9(60.00)$ & 0.843 \\
\hline No & $10(52.63)$ & $48(54.55)$ & $6(40.00)$ & \\
\hline EF & $57.32 \pm 6.26$ & $58.52(5.50)$ & $61.60(3.60)$ & 0.065 \\
\hline \multicolumn{5}{|l|}{ Hypertension } \\
\hline Yes & $13(68.42)$ & $36(40.91)$ & $12(80.00)$ & 0.004 \\
\hline No & $6(31.58)$ & $52(59.09)$ & $3(20.00)$ & \\
\hline \multicolumn{5}{|l|}{ Diabetes } \\
\hline Yes & 15(78.95) & $64(72.73)$ & $12(80.00)$ & 0.747 \\
\hline No & $4(21.05)$ & 24(27.27) & $3(20.00)$ & \\
\hline
\end{tabular}




\begin{tabular}{|lllll|}
\hline Characteristic & Steel suture & Titanium plates & Mixed fixation & $\mathbf{p}$ \\
\hline Yes & $11(57.89)$ & $52(59.09)$ & $14(93.33)$ & 0.035 \\
\hline No & $8(42.11)$ & $36(40.91)$ & $1(6.67)$ & \\
\hline Operation time & $3.24 \pm 0.87$ & $3.11 \pm 0.73$ & $2.80 \pm 0.92$ & 0.246 \\
\hline Postoperative time & $13.79 \pm 6.47$ & $12.36 \pm 8.88$ & $11.93 \pm 8.17$ & 0.769 \\
\hline Cortical thickness & $2.44 \pm 0.55$ & $2.93 \pm 0.60$ & $2.96 \pm 0.57$ & 0.004 \\
\hline Sternal thickness & $11.92 \pm 1.48$ & $12.32 \pm 1.59$ & $12.59 \pm 0.85$ & 0.418 \\
\hline Sternal score & $3.04 \pm 1.13$ & $2.44 \pm 0.98$ & $2.67 \pm 0.82$ & 0.057 \\
\hline
\end{tabular}


Table 3

Demographic and clinic characteristics for eligible patients after PSM

\begin{tabular}{|c|c|c|c|c|}
\hline Characteristic & Steel suture & Titanium plates & Mixed fixation & $\mathbf{p}$ \\
\hline $\mathrm{n}$ & 19 & 68 & 15 & \\
\hline \multicolumn{5}{|l|}{ Gender } \\
\hline Female & 12(63.16) & $45(66.18)$ & $9(60.00)$ & 0.891 \\
\hline Male & $7(36.84)$ & 23(33.82) & $6(40.00)$ & \\
\hline Age & $51.32 \pm 14.83$ & $57.43 \pm 9.20$ & $50.40 \pm 11.64$ & 0.018 \\
\hline High & $167.63 \pm 11.40$ & $165.66 \pm 7.25$ & $167.20 \pm 5.09$ & 0.56 \\
\hline Weight & $65.37 \pm 13.04$ & $66.82 \pm 11.01$ & $64.80 \pm 11.07$ & 0.771 \\
\hline BMI & $23.04 \pm 2.54$ & $24.31 \pm 3.59$ & $23.07 \pm 2.85$ & 0.201 \\
\hline \multicolumn{5}{|l|}{ NYHA } \\
\hline ० & $5(26.32)$ & $21(30.88)$ & $2(13.33)$ & 0.147 \\
\hline ( & $5(26.32)$ & $22(32.35)$ & $9(60.00)$ & \\
\hline ૧ & $8(42.11)$ & $25(36.76)$ & $4(26.67)$ & \\
\hline प & $1(5.26)$ & $0(0.00)$ & $0(0.00)$ & \\
\hline \multicolumn{5}{|c|}{ Pulmonary hypertension } \\
\hline Yes & $13(68.42)$ & $59(86.76)$ & $12(80.00)$ & 0.173 \\
\hline No & $6(31.58)$ & $9(13.24)$ & $3(20.00)$ & \\
\hline \multicolumn{5}{|l|}{ LIMAT } \\
\hline Yes & $9(47.37)$ & $31(45.59)$ & $9(60.00)$ & 0.836 \\
\hline No & $10(52.63)$ & $37(54.41)$ & $6(40.00)$ & \\
\hline EF & $57.32(6.26)$ & $58.87(5.43)$ & $61.60(3.60)$ & 0.072 \\
\hline \multicolumn{5}{|l|}{ Hypertension } \\
\hline Yes & $13(68.42)$ & $33(48.53)$ & $12(80.00)$ & 0.044 \\
\hline No & $6(31.58)$ & $35(51.47)$ & $3(20.00)$ & \\
\hline \multicolumn{5}{|l|}{ Diabetes } \\
\hline Yes & 15(78.95) & $51(75.00)$ & $12(80.00)$ & 0.882 \\
\hline No & $4(21.05)$ & $17(25.00)$ & $3(20.00)$ & \\
\hline
\end{tabular}




\begin{tabular}{|lllll|}
\hline Characteristic & Steel suture & Titanium plates & Mixed fixation & $\mathbf{p}$ \\
\hline Yes & $11(57.89)$ & $41(60.29)$ & $14(93.33)$ & 0.042 \\
\hline No & $8(42.11)$ & $27(39.71)$ & $1(6.67)$ & \\
\hline Operation time & $3.24 \pm 0.87$ & $3.02 \pm 0.76$ & $2.80 \pm 0.92$ & 0.291 \\
\hline Postoperative time & $13.79 \pm 6.47$ & $11.97 \pm 8.81$ & $11.93 \pm 8.17$ & 0.692 \\
\hline Cortical thickness & $2.44 \pm 0.55$ & $2.94 \pm 0.60$ & $2.96 \pm 0.57$ & 0.004 \\
\hline Sternal thickness & $11.92 \pm 1.48$ & $12.26 \pm 1.59$ & $12.59 \pm 0.85$ & 0.429 \\
\hline Sternal score & $3.04 \pm 1.13$ & $2.51 \pm 0.99$ & $2.67 \pm 0.82$ & 0.131 \\
\hline
\end{tabular}

\section{Factors influencing sternal healing}

Figure 3 showed the rate of good sternal healing over time from 1 to 24 months. The average total sternal healing score in the $S$ gropu was $2.56 \pm 1.52$. $56 \%$ patients showed good healing. In the $L$ group, the mean total sternal healing score was $2.63 \pm 1.12$ and good healing was observed in $62.5 \%$ patients. Poor healing was more frequently found in the lower sternum than others. Table 4 showed the results of the analyses of the influence factors for sternal healing score. In the $S$ group, Sternal score was only correlated with postoperative time $(H R=0.18,95 \% \mathrm{Cl}: 0.135-0.225, p<0.001)$. In the $L$ group, old people had a higher risk of poor sternal healing than young (Age, $\mathrm{HR}=-0.028,95 \% \mathrm{Cl}:-0.05-0.006, p=0.013$ ). Patients with left internal mammary artery grafting (LIMAG) had a high risk of poor sternal healing $(\mathrm{HR}=-0.444, \mathrm{Cl}:-0.869-0.019, \mathrm{p}=0.045)$. It should be noted that BMI was not statistically significant. The $\mathrm{Q}-\mathrm{Q}$ plot was uesd to verify the normality and linear relationship of linear regression (Fig. 4).

Table 4

Influence factors for sternal healing score

\begin{tabular}{|lllll|}
\hline & Group of short term & $\mathbf{p}$ & Group of long term & $\mathbf{p}$ \\
\hline Age & $-0.003[-0.011,0.005]$ & 0.387 & $-0.028[-0.05,-0.006]$ & $0.013^{\star}$ \\
\hline BMI & $-0.002[-0.029,0.025]$ & 0.889 & $-0.01[-0.077,0.057]$ & 0.765 \\
\hline LIMAT & $-0.104[-0.288,0.08]$ & 0.276 & $-0.444[-0.869,-0.019]$ & $0.045^{*}$ \\
\hline EF & $0.017[-0.003,0.037]$ & 0.084 & $0.021[-0.014,0.056]$ & 0.242 \\
\hline Postoperative time & $0.18[0.135,0.225]$ & $<0.001^{\star * *}$ & $0.008[-0.029,0.045]$ & 0.655 \\
\hline Cortical thickness & $-0.021[-0.172,0.13]$ & 0.783 & $-0.043[-0.462,0.376]$ & 0.840 \\
\hline Sternal thickness & $-0.024[-0.089,0.041]$ & 0.471 & $0.001[-0.138,0.14]$ & 0.995 \\
\hline Titanium plates & $-0.162[-0.497,0.173]$ & 0.35 & $-0.076[-0.556,0.404]$ & 0.758 \\
\hline Mixed fixation & $-0.036[-0.442,0.37]$ & 0.863 & $-0.336[-1.006,0.334]$ & 0.333 \\
\hline
\end{tabular}




\section{Transverse displacement}

In this study, we found transverse separation of sternum in 17 patients. This problem existed in 16 patients with titanium plates fixation and 1 patients with steel wire fixation, while there was no one with mixed fixation. The transverse displacement mainly occurred in the lower sternum (The levels of main pulmonary artery and aortic root). Only one patient's sternum had a score of 2 at the level of transverse deviation, and the rest had a score of 0 .

Figure 5 showed the model of sternum after median sternotomy. The case group included patients closed sternum with steel wire fixation along and the patients with mixed fixation. The patients who used titinium plates fixation were selected as control group. By binary logistic regression, It could be found that steel wire fixation was a favorable factor to prevent the transverse displacement of sternum $(H R=0.122$, $95 \% \mathrm{Cl}: 0.007-0.651, \mathrm{p}=0.047)$.

\section{Discussion}

Bone healing is mainly affected by macroscopic factors (biomechanics and blood supply) as well as microscopic factors (such as molecular biology)[13]. BitKover found that there was no sternal healing 3 months after median sternotomy in a prospective computed tomography scan study[14]. Advanced age as an independent risk factor is not only related to sternal postoperative complications, but also affects sternum healing. Studies have confirmed the importance of immune mechanisms and inflammatory response in bone healing[15]. The cells that is important in inflammatory responses (macrophages, $T$ cells, and mesenchymal stem cells) are related to age. The number and activity of osteochondrocytes and their progenitor cells in the bone marrow of the elderly are lower than young. In addition, advanced age is a high-risk factor for vascular diseases which is closely related to the ability of blood vessels to transport blood flow and it leads to poor blood perfusion of sternum. The choice of bypass vessels is important during coronary artery bypass surgery. Puskas[16] confirmed that transplantation of the internal mammary artery as a bypass vessel significantly improved the long-term survival rate. In clinical practice, almost all cardiothoracic surgeon choose the internal mammary artery as the first choice for transplantation. Interception of the internal mammary artery will not only increase the chance of sternal complications, such as mediastinal infection and sternal opening, but also affect sternum healing[17]. $\mathrm{BMI}>35 \mathrm{~kg} / \mathrm{m}^{2}$ as an independent risk factor influencing the score of sternum have been reported in previous literature[18], but the BMI of Asians is generally lower than that of Europeans[19]. In this study, only five patients had a BMI greater than $30 \mathrm{~kg} / \mathrm{m}^{2}$. All of them were fixed with sternum plate, so this study failed to get positive results related to BMI. During follow-up we found that a small number of patients with dysplasia of the lower sternal segment had difficulty in achieving sternal healing based on imaging scan after surgery. The cortical bone and the thickness of the sternum was used as an indicator to measure sternum development. We found that whether the thickness of the sternum or the cortical bone thickness was not related to sternal healing score. 
Several forces such as breathing and coughing act on the sternum and load the sternum through a combination of lateral shear and transverse shear. Losanoff et al.[20] confirmed that the lateral tension of the thorax is mainly concentrated in the lower part of the sternum. It is due to the confluence of multiple ribs in the lower sternum and the greater mobility of the chest wall in the area during breath and exercise[21]. Therefore, healing of the lower sternum is poor. Minimal anteroposterior movement of the sternal halves will lead to the result that the cortical bone on one side of the sternum enter the cancellous bone of the other side of sternum. That can affect bone fusion even without frank dissociation[22]. Therefore, the method of sternal closure seems to be important to long-term sternal healing. Mechanical studies demonstrated that rigid plate fixation of the sternum results in superior mechanical properties compared with wire fixation[23]. COL David J. Cohen[24] compared the biomechanics of different sternal closure techniques and found that the plates were stiffer than the figure-of-eight wire constructs in the transverse shear direction.

The main reasons for the differences between the results of this study and the conclusion of COL David J. Cohen are as follows: The sternum plates used in the two experiments were different. Failure of the wire system usually involves the wire cutting into the bone under loads. Within the maximum shear force that steel wire can bear, the stability of eight-shaped steel wire fixation sternum may be stronger than that of sternum plate. The vitro experiment was difficult to imitate the complex biomechanics of human body completely by the force of simple direction.

Titinium plates provide more stability than wire cerclage alone, but it lack the posterior sternal stabilization. 360-degree rigid sternal fixation with combination of plates and wire cerclage described here has been performed in 2 patients to date, with good sternal healing (sternal healing score $\geq 3$ ). Taylor M. James once proposed a similar method to fix the sternum and this method had been employed in 40 patients, with a zero incidence of deep sternal wound infection[25]. Wire cerclage along with rigid sternal plates that helps stabilize the sternum not only in the posterior plane but also in the lateral plane may reduce the amount of mechanical stress put on the plate. Owing to the complication of this method, we recommend considering this technique for especially high-risk patient who are old people, or those with morbid obesity. According to biomechanics, we can use this method to fix the lower part of the sternum, while the upper part of the sternum could be fixed with titanium plate or eight-shape wire alone (Fig. 5).

The limitations of this study inherent was a retrospective review. There was obvious selection bias regarding whether a patient received titanium plate reinforcement, because this technique was usually used in old people,or those with morbidly obesity. We attempted to control for this bias by PSM. Lastly, because of the small number of patients fixed sternum with this new method, our ability to examine its stiff was limited.

In summary, advanced age and internal mammary artery interception are risk factors that affect sternal healing based on imaging findings. this new method of sternal closure provides an effective way of 
ensuring sternal stability of both sternal plates and reduces the risk for complication after cardiac surgery in high-risk patients.

\section{Abbreviations}

BMl: Body mass index

PSM:propensity score matching

LIMAG『Internal mammary artery dissociation

$*: p<0.05, * *: p<0.01, * \star *: p<0.001$

\section{Declarations}

\section{Author information}

\section{Affiliations}

Suzhou University, Ganjiang East Street 333, Changzhou, China

Xuanren Long

Department of Cardiothoracic Surgery, The Third Affiliated Hospital of Soochow University $\mathbb{}$ Changzhou First People's Hospital, Juqian Street 185, Changzhou, China.

Kun Mei\&Yongxiang Qian\&Xiaoyin Zhang\&Bin Wang\&Dongmei Di

\section{Author contributions}

X.R. Long made design of this study.

X.R. Long analyzed and interpreted the factors affecting sternum healing.

X.R. Long gathered materials of this study and was a major contributor in writing the manuscript.

All authors participated in the final revision of the manuscript

All authors read and approved the final manuscript.

Corresponding author

Correspondence to Xuanren Long

\section{Ethics approval and consent to participate}


This study was approved by the Committee of Ethics of the Third affiliated Hospital of soochow University, Changzhou, China.

\section{Consent for publication}

Not applicable

\section{Availability of data and materials}

The datasets used during the current study are available from the corresponding author on reasonable request.

\section{Conflicts of interest statement}

The authors declare that they have no competing interests.

\section{Funding}

The financial support of this study are provided by Young Talent Development Plan of Changzhou Health Commission. [CZQM2020004]

\section{Acknowledgements}

Not applicable

\section{References}

1. Dalton ML, Connally SR. Median sternotomy. Surg Gynecol Obstet 1993;176:615-24.

2. Losanoff JE, Jones JW, Richman BW . Primary closure of median sternotomy: techniques and principles. Cardiovasc Surg 2002;10(April (2)):102-10.

3. Shahian DM, O'Brien SM, Filardo G, Ferraris V A, Haan CK, Rich JB, et al.The Society of Thoracic Surgeons 2008 cardiac surgery risk models: part1-coronary artery bypass grafting surgery. Ann Thorac Surg. 2009;88(1 suppl):S2-22.

4. De Paulis R, de Notaris S, Scaffa R, Nardella S, Zeitani J, Del Giudice C, et al.The

5. effect of bilateral internal thoracic artery harvesting on superficial and deepsternal infection: The role of skeletonization. J Thorac Cardiovascr Surg. 2005;129:536-43.

6. Wang, Stewart C , Rinkinen, et al. Cross-sectional area of the abdomen predicts complication incidence in patients undergoing sternal reconstruction[J]. Journal of Surgical Research: Clinical and Laboratory Investigation, 2014.

7. Golosow $L M$, Wagner $J D$, Feeley $M$, et al. Risk factors for predicting surgical salvage of sternal wound-healing complications.[J]. Annals of Plastic Surgery, 1999, 43(1):30. 
8. BRUCE J, DRURY N, POOBALAN A S, et al. Bruce J, Drury N, Poobalan AS, Jeffrey RR, Smith WCS, Chambers WAThe prevalence of chronic chest and leg pain following cardiac surgery: a historical cohort study. Pain 104: 265-273 [J]. Pain, 2003, 104(1-2): 265-73.

9. Gjeilo K H , Klepstad P, Wahba A , et al. Chronic pain after cardiac surgery: a prospective study[J]. Acta Anaesthesiol Scand, 2014, 54(1).

10. Raab S , Reindl S, Schuller Z, et al. Sternal Reclosure Using Sternal Clips in Patients with Deep Sternal Wound Infection[J]. The Thoracic and Cardiovascular Surgeon, 2019, 67(S 01):-.

11. Wu $Y$, Wang $J$, Dai $J$, et al. Is vacuum-assisted closure therapy feasible for children with deep sternal wound infection after cardiac surgery? The pooling results from current literature[J]. Artificial Organs, 2021.

12. Sturmer T, Rothman KJ, Avorn J, et al. Treatment effects in the presence of unmeasured confounding: dealing with observations in the tails of the propensity score distribution-a simulation study. Am J Epidemiol 2010;172:843-54.

13. Zhang Z. Propensity score method: a nonparametric technique to reduce model dependence. Ann Transl Med 2017;5:7

14. MARSELL R, EINHORN T A. The biology of fracture healing [J]. Injury-international Journal of the Care of the Injured, 2011, 42(6): 551-5.

15. Grdlund, B, Bitkover, et al. Postoperative mediastinitis in cardiac surgery microbiology and pathogenesis.[J]. European Journal of Cardio-Thoracic Surgery, 2002, 21(5):825-825.

16. Rose S, Maffulli N . Hip fractures. An epidemiological review.[J]. Bulletin, 1999, 58(4):197.

17. Puskas, Thourani, Marshall, et al. Clinical Outcomes, Angiographic Patency, and Resource Utilization in 200 Consecutive Off-Pump Coronary Bypass Patients[J]. Annals of Thoracic Surgery, 2001.

18. DAI C, LU Z, ZHU H, et al. Bilateral internal mammary artery grafting and risk of sternal wound infection: evidence from observational studies [J]. The Annals of thoracic surgery, 2013, 95(6): 193845.

19. Pech T, Kania A, Fehlberg W, et al. Treatment of Sternal Osteomyelitis after Median Sternotomy in 130 Patients with Pedicled Myocutaneous Latissimus Flap[J]. Zentralblatt für Chirurgie - Zeitschrift für Allgemeine, Viszeral-, Thorax- und Gef?chirurgie, 2018, 143(S 01):S51-S60.

20. Hauck K, Hollingsworth B, Morgan L. BMI differences in 1st and 2nd generation immigrants of Asian and European origin to Australia[J]. Health \& Place, 2011, 17(1):78-85.

21. Julian, E, Losanoff, et al. Biomedfdschanical comparison of median sternotomy closures[J]. Annals of Thoracic Surgery, 2004.

22. CASHA A R, MANCHE A, GATT R, et al. Mechanism of sternotomy dehiscence [J]. Interactive cardiovascular and thoracic surgery, 2014, 19(4): 617-21.

23. Nishimura T, Kurihara C, Sakano Y, Kyo S. Sternalock plating system for elderly post-sternotomy patients. J Artif Organs 2014;17(03):288-290. 
24. Allen K B , Thourani V H, Naka Y, et al. Randomized, multicenter trial comparing sternotomy closure with rigid plate fixation to wire cerclage[J]. Journal of Thoracic \& [24]Cardiovascular Surgery, 2016, 153(4):888-896.e1.Cohen C , Griffin L V . A biomechanical comparison of three sternotomy closure techniques.[J]. Annals of Thoracic Surgery, 2002, 73(2):563-568.

25. James T M , Nores M A , Stamou S . A Technique for 360-Degree Rigid Sternal Fixation with Sternal Plates and Wire Cerclage[J]. The Thoracic and Cardiovascular Surgeon, 2019:-.

\section{Tables}

Table 1 Consistency test of sternal healing score

\begin{tabular}{|ll|}
\hline & Kapper vaule \\
\hline$\square$ & 0.852 \\
\hline$\square$ & 0.831 \\
\hline$\square$ & 0.798 \\
$\square$ & 0.882 \\
$\square$ & 0.799 \\
\hline
\end{tabular}

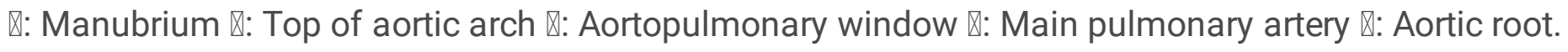
Kapper vaule>0.6:The two groups were significantly the same.

Table 2 Demographic and clinic characteristics for eligible patients 
Characteristic

$\mathrm{n}$

Gender

Female

Male

Age

High

Weight

BMI

NYHA

\begin{tabular}{l}
$\square$ \\
$\square$ \\
\hline \\
\hline \\
Pulmonary hypertension
\end{tabular}

Yes

No

LIMAT

Yes

No

EF

Hypertension

Yes

No

Diabetes

Yes

No

History of MI

Yes

11(57.89)

5(26.32)

5(26.32)

8(42.11)

1(5.26)

13(68.42)

6(31.58)

9(47.37)

10(52.63)

13(68.42)

6(31.58)

15(78.95)

4(21.05)
Titanium plates

88

56(63.64)

32(36.36)

$51.32 \pm 14.83 \quad 60.50 \pm 10.02$

$167.63 \pm 11.40 \quad 164.85 \pm 7.59$

$65.37 \pm 13.04 \quad 66.34 \pm 10.73$

$23.04 \pm 2.54 \quad 24.36 \pm 3.37$

77(87.50)

11(12.50)

12(80.00)

0.116

3(20.00)

$57.32 \pm 6.26$

36(40.91)

52(59.09)

12(80.00)

0.004

3(20.00)

6(40.00)

61.60(3.60)

0.065

58.52(5.50)

64(72.73)

12(80.00)

0.747

24(27.27)

3(20.00) 


\begin{tabular}{lllll} 
No & $8(42.11)$ & $36(40.91)$ & $1(6.67)$ & \\
\hline Operation time & $3.24 \pm 0.87$ & $3.11 \pm 0.73$ & $2.80 \pm 0.92$ & 0.246 \\
\hline Postoperative time & $13.79 \pm 6.47$ & $12.36 \pm 8.88$ & $11.93 \pm 8.17$ & 0.769 \\
\hline Cortical thickness & $2.44 \pm 0.55$ & $2.93 \pm 0.60$ & $2.96 \pm 0.57$ & 0.004 \\
\hline Sternal thickness & $11.92 \pm 1.48$ & $12.32 \pm 1.59$ & $12.59 \pm 0.85$ & 0.418 \\
\hline Sternal score & $3.04 \pm 1.13$ & $2.44 \pm 0.98$ & $2.67 \pm 0.82$ & 0.057
\end{tabular}

Table 3 Demographic and clinic characteristics for eligible patients after PSM 
Characteristic

Gender

Female

Male

Age

High

Weight

BMI

NYHA

\begin{tabular}{l}
\hline \\
\hline \\
\hline \\
\hline \\
Pulmonary hypertension
\end{tabular}

\begin{tabular}{l} 
Yes \\
No \\
\hline LIMAT
\end{tabular}

Yes

No

EF

Hypertension

\begin{tabular}{lllll} 
Yes & $13(68.42)$ & $33(48.53)$ & $12(80.00)$ & 0.044 \\
\hline No & $6(31.58)$ & $35(51.47)$ & $3(20.00)$ &
\end{tabular}

Diabetes

\begin{tabular}{lcccc} 
Yes & $15(78.95)$ & $51(75.00)$ & $12(80.00)$ & 0.882 \\
\hline No & $4(21.05)$ & $17(25.00)$ & $3(20.00)$ & \\
\hline History of Ml & & & & \\
\hline Yes & $11(57.89)$ & $41(60.29)$ & $14(93.33)$ & 0.042 \\
\hline
\end{tabular}




\begin{tabular}{lllll} 
No & $8(42.11)$ & $27(39.71)$ & $1(6.67)$ & \\
\hline Operation time & $3.24 \pm 0.87$ & $3.02 \pm 0.76$ & $2.80 \pm 0.92$ & 0.291 \\
\hline Postoperative time & $13.79 \pm 6.47$ & $11.97 \pm 8.81$ & $11.93 \pm 8.17$ & 0.692 \\
\hline Cortical thickness & $2.44 \pm 0.55$ & $2.94 \pm 0.60$ & $2.96 \pm 0.57$ & 0.004 \\
\hline Sternal thickness & $11.92 \pm 1.48$ & $12.26 \pm 1.59$ & $12.59 \pm 0.85$ & 0.429 \\
\hline Sternal score & $3.04 \pm 1.13$ & $2.51 \pm 0.99$ & $2.67 \pm 0.82$ & 0.131
\end{tabular}

Table 4 Influence factors for sternal healing score

\begin{tabular}{lllll} 
& Group of short term & $p$ & Group of long term & $p$ \\
\hline Age & $-0.003[-0.011,0.005]$ & 0.387 & $-0.028[-0.05,-0.006]$ & $0.013^{\star}$ \\
\hline BMI & $-0.002[-0.029,0.025]$ & 0.889 & $-0.01[-0.077,0.057]$ & 0.765 \\
\hline LIMAT & $-0.104[-0.288,0.08]$ & 0.276 & $-0.444[-0.869,-0.019]$ & $0.045^{\star}$ \\
\hline EF & $0.017[-0.003,0.037]$ & 0.084 & $0.021[-0.014,0.056]$ & 0.242 \\
\hline Postoperative time & $0.18[0.135,0.225]$ & $<0.001^{\star \star \star}$ & $0.008[-0.029,0.045]$ & 0.655 \\
\hline Cortical thickness & $-0.021[-0.172,0.13]$ & 0.783 & $-0.043[-0.462,0.376]$ & 0.840 \\
\hline Sternal thickness & $-0.024[-0.089,0.041]$ & 0.471 & $0.001[-0.138,0.14]$ & 0.995 \\
\hline Titanium plates & $-0.162[-0.497,0.173]$ & 0.35 & $-0.076[-0.556,0.404]$ & 0.758 \\
\hline Mixed fixation & $-0.036[-0.442,0.37]$ & 0.863 & $-0.336[-1.006,0.334]$ & 0.333
\end{tabular}

\section{Figures}




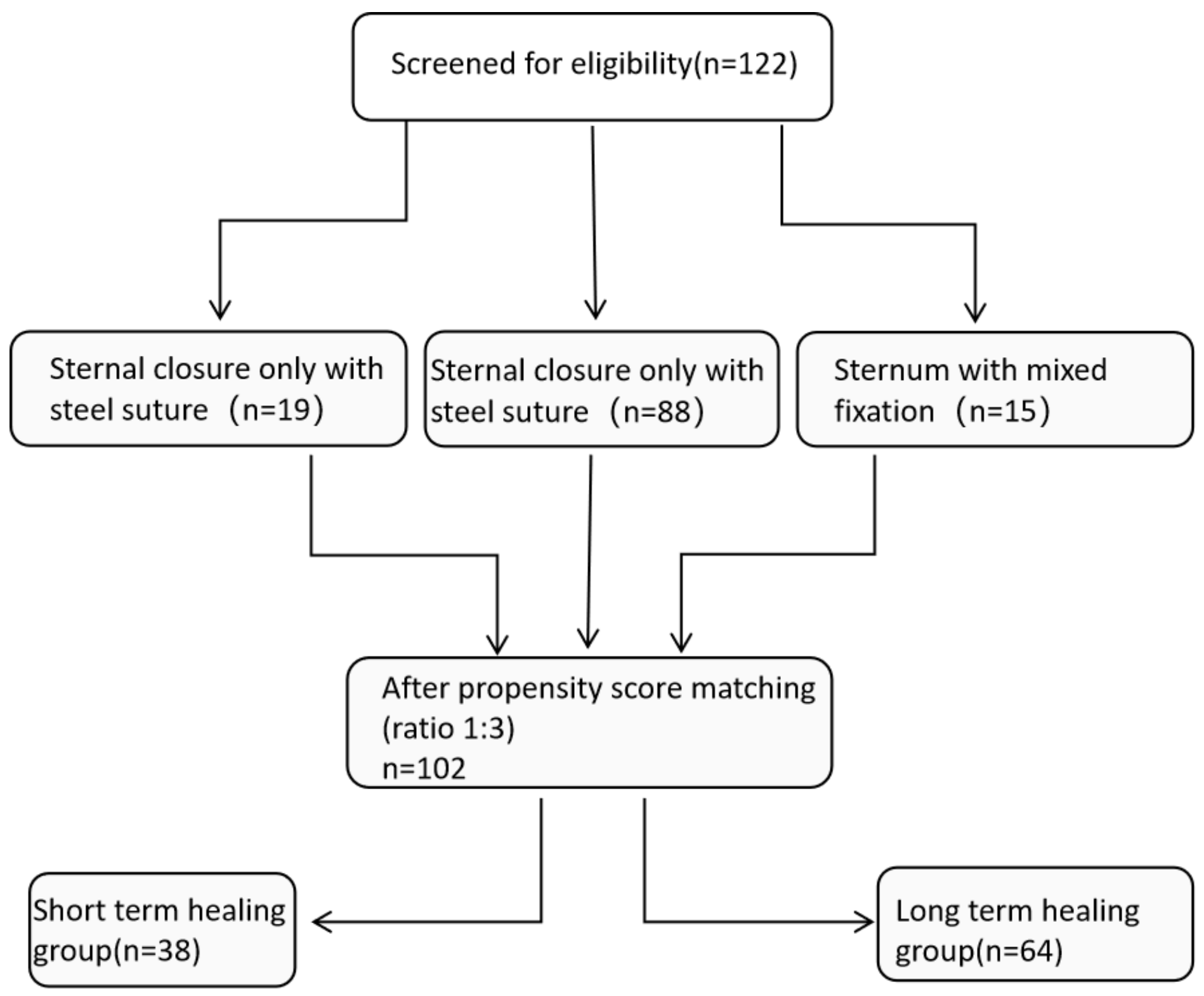

Figure 1

Flow chart for the data screening 


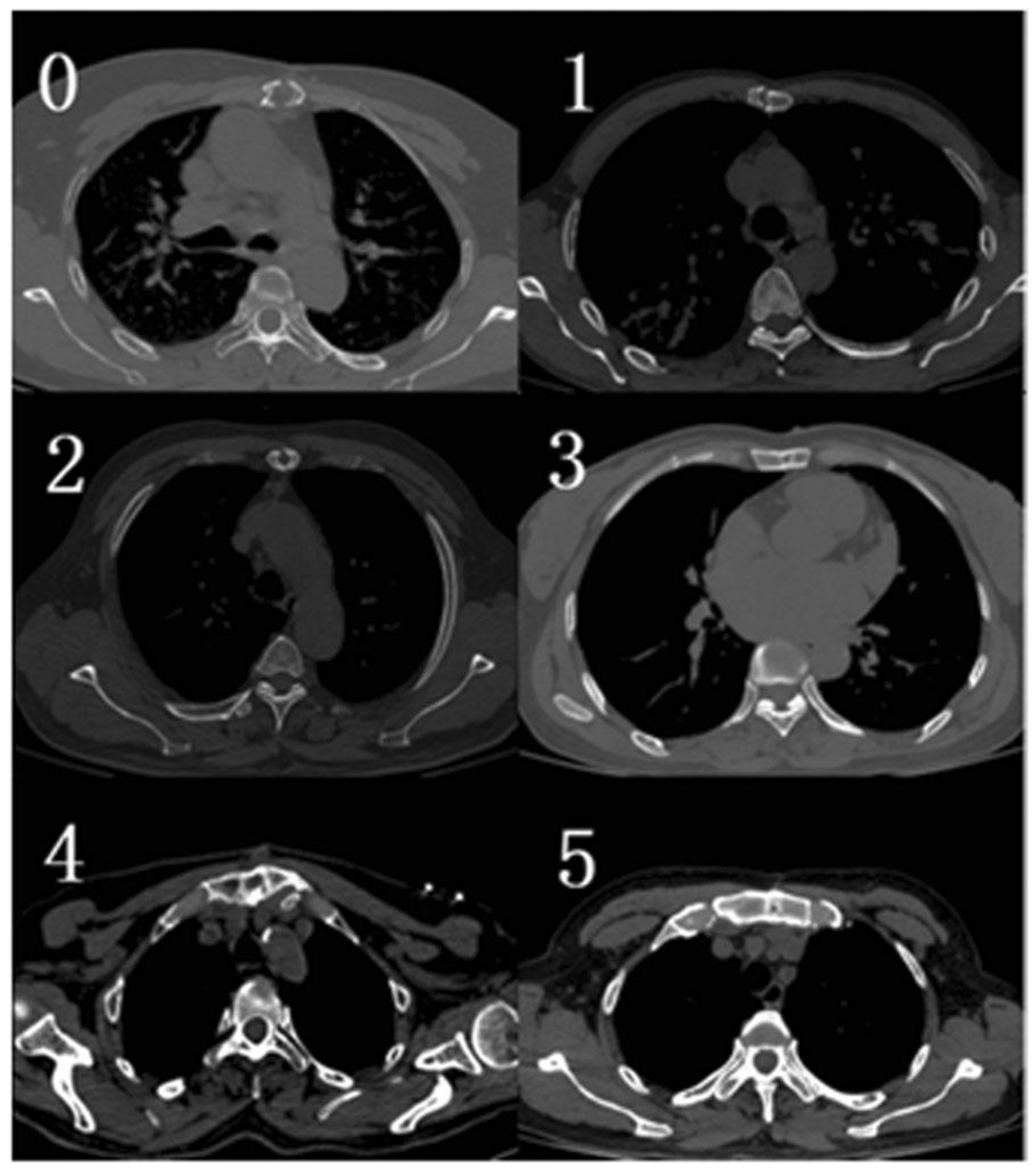

\section{Figure 2}

Axial computed tomography scan images representative of each score on 6-point scale. Each score was defined as follows: (0) no sign of healing (clear lack of healing, nonunion, sternal separation); (1) minimal healing (sternal separation, lack of bridging bone); (2) mild healing (sternal separation with hazy, immature bone formation); (3) moderate healing (partial bridging bone indicative of sternal stability); (4) partial synthesis (significant bridging bone); (5) complete synthesis (complete bridging bone). 


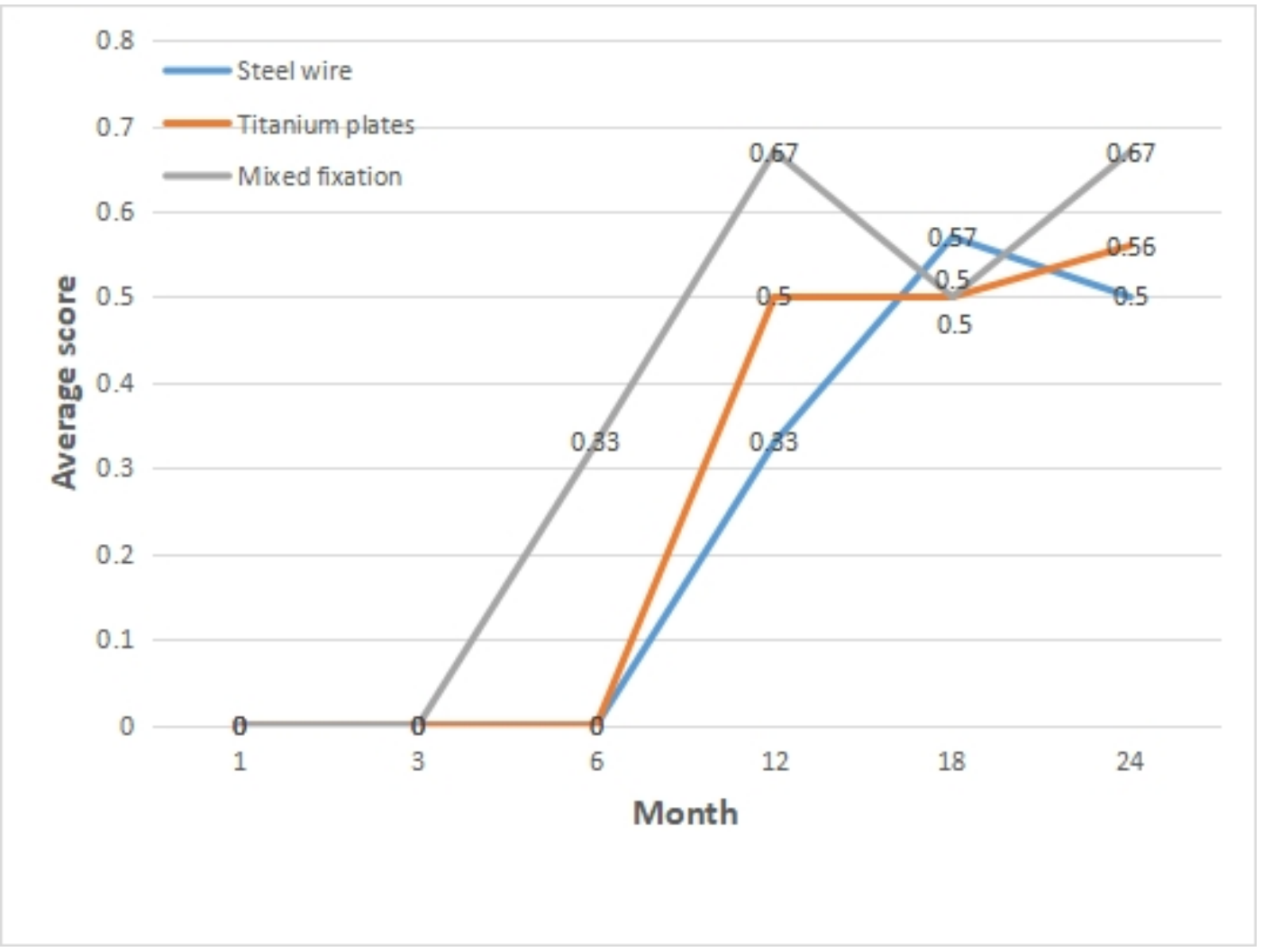

\section{Figure 3}

Rate of good sternal healing over time from 1-24 months

Q-Q Plot of short term group

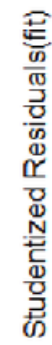

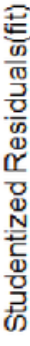

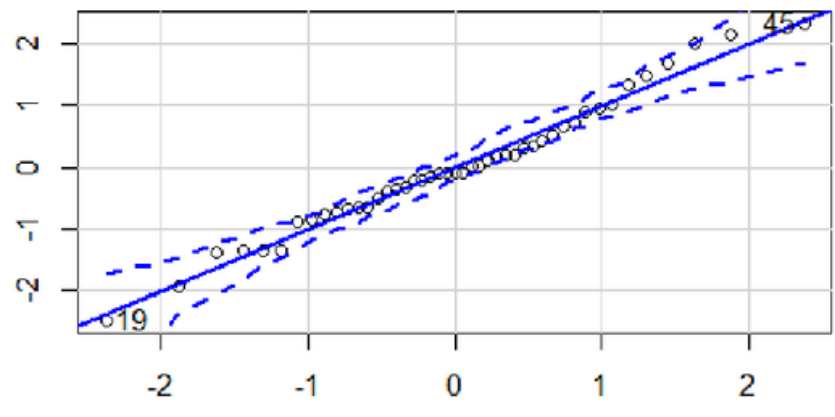

t Quantiles
Q-Q Plot of long term group

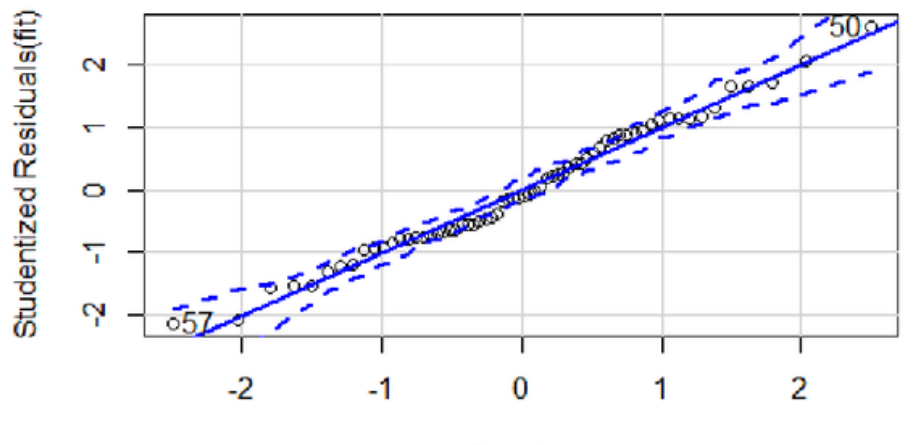

t Quantiles

\section{Figure 4}

If the two distributions are similar, the Q-Q diagram tends to fall on $\mathrm{y}=\mathrm{X}$-ray. If the two distributions are linearly correlated, the points tend to fall on a straight line on the Q-Q graph. 

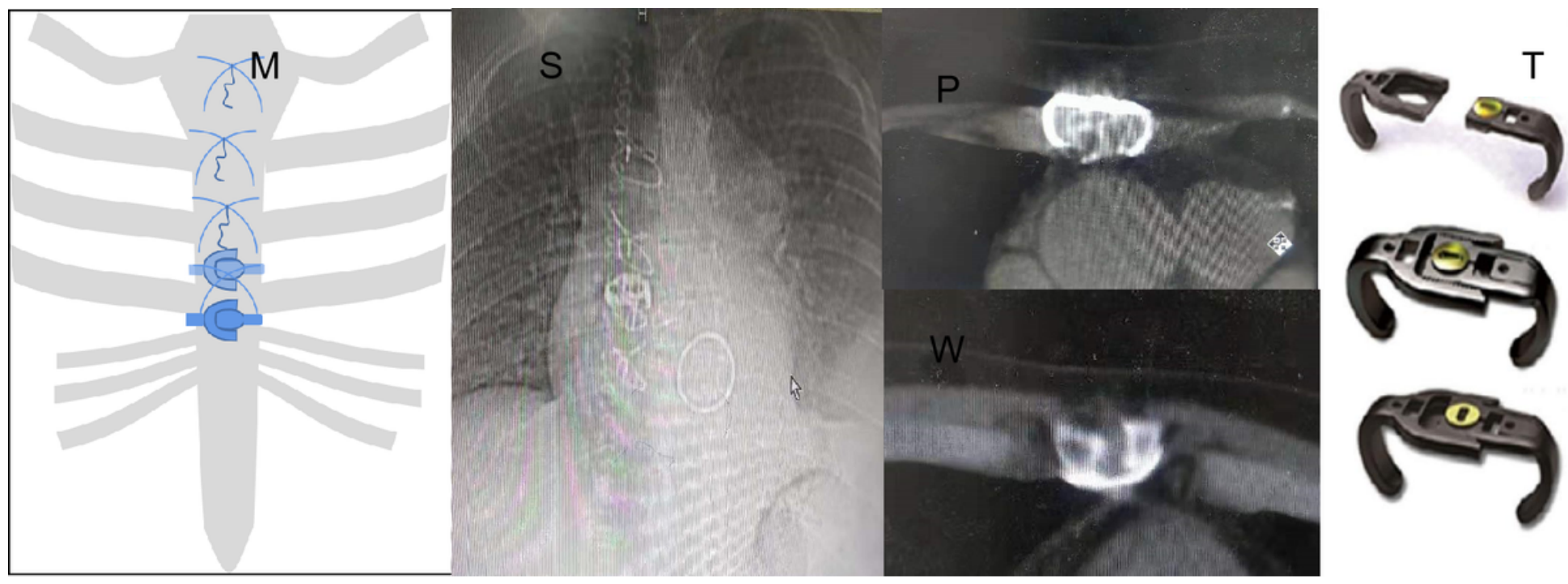

Figure 5

(M):model of sternum after median sternotomy. (S):sternal closed with the new method. (P): closed using titinium plates; $(\mathrm{W})$ : closed using wires. The transverse displacement of sternum occurred in $\mathrm{P}$ and $\mathrm{W}$ images. (T):titinium plates 